\title{
Depression care and prevalence in HIV-positive individuals
}

This article was published in the following Dove Press journal:

Neurobehavioral HIV Medicine

28 August 2010

Number of times this article has been viewed

\author{
Raymond L Ownby' \\ Robin J Jacobs' \\ Drenna Waldrop-Valverde ${ }^{2}$ \\ Felicia Gould ${ }^{2}$ \\ 'Department of Psychiatry \\ and Behavioral Medicine, Nova \\ Southeastern University, Fort \\ Lauderdale, Florida, USA; 'Department \\ of Psychiatry and Behavioral Sciences, \\ University of Miami Miller School \\ of Medicine, Miami, Florida, USA
}

\begin{abstract}
Depression is among the most common neuropsychiatric disturbances seen in individuals with HIV infection. Associated with sad mood, disturbed sleep and appetite, and low energy, the symptoms of depression may be difficult to distinguish from those of the infection itself. Depression has enormous clinical significance in this group of patients, not only for the misery and poor quality of life it causes but also for its negative effect on patients' sexual risk behavior, substance use, and medication adherence. Depression has been associated with patients' immune system functioning and with poorer disease outcomes. Although it can be effectively treated in most individuals, fewer than one half of patients with depression are correctly diagnosed and still fewer receive adequate treatment. Effective treatments for depression in this group include antidepressant medication, individual and group psychotherapy, and social support interventions. Given the significance of this common yet under-recognized problem, clinicians should be aware of the implications of failing to aggressively treat depression in HIV-infected individuals.
\end{abstract}

Keywords: HIV, depression, SSRI, cognitive-behavioral therapy, neuroinflammation, stigma

\section{Introduction}

Depression is among the most common neuropsychiatric disorders that affect individuals with HIV infection. Depression has a dramatic effect on patients' quality of life. ${ }^{1}$ Depression has an important impact on the course and outcome of HIV infection through its effects on patients' adherence to medication regimens and via psychoneuroimmunological mechanisms. In spite of its importance, it is likely that depression is under-recognized and under-treated in patients with HIV infection.

This review will highlight the prevalence of depression among those with HIV infection, discuss its importance, and review treatment options. Consistent with the biopsychosocial model of depression, this review will emphasize not only the biological aspects of depression and its treatment in those with HIV infection, but also focus on its psychological and social aspects. The medical focus of the treatment of depression is often on medications, and we refer to several excellent and detailed reviews of the topic in the section on the medical treatment of depression; our central purpose in this review, however, is not to provide a detailed review of the use of antidepressant medications.

Correspondence: Raymond L Ownby Department of Psychiatry and Behavioral Medicine, Nova Southeastern University, Room I477, 3200 South University Drive, Fort Lauderdale, FL 33316, USA

$\mathrm{Tel}+$ I 954262 I48I

Fax + I 9542623753

Emailro7I@nova.edu

\section{Prevalence} widely, from $0 \%$ to more than $33 \%$ depending on patient population and method of ascertainment. The data from probably the best single study come from the HIV Cost
Estimates of the prevalence of depressive disorders in this group of patients range 
and Services Utilization Study, which showed that as many as $37 \%$ of HIV-infected individuals suffered from major depression, ${ }^{2}$ although alternate methods suggested a lower rate of depression in this sample. ${ }^{3}$ A 2001 meta-analysis of prevalence studies ${ }^{4}$ showed ranges of depression in HIVinfected individuals from $0 \%$ to $22.5 \%$. Conclusions drawn from the meta-analysis indicated that persons with HIV infection were about twice as likely to be depressed as were uninfected comparison subjects, with an overall rate of depression of $9.4 \%$ in HIV-positive persons compared with a rate of $5.2 \%$ in the comparison group.

None of the readily identifiable studies of the prevalence of depression in persons with HIV infection depression was population based; that is, none was based on an assessment of a sample of persons representative of a general population. Most studies were thus based on groups of persons seeking treatment. This fact suggests that estimates of the prevalence of depression may be biased upward since persons seeking treatment might be expected to be more distressed (including depressed) than persons who are not distressed. In fact, since the prevalence of depression in primary care clinics has been estimated to be as high as $37 \%,{ }^{5}$ it is not clear that the occurrence of depression in persons with HIV infection is substantially greater than that which occurs in other persons with chronic diseases.

In order to address this issue, we completed an analysis of a population-based dataset, the National Health and Nutrition Survey Examination (NHANES) ${ }^{6}$ for the years 2005-2006. NHANES is a large ongoing data collection project that provides laboratory, questionnaire, and examination data on a group of individuals selected to be representative of the population of the US ( $n=3,127$ for these analyses). The dataset included ELISA testing for HIV antibodies with follow-up Western blot confirmation in individuals aged 18-49 years. These data also included self-report data on depressive symptoms from the Patient Health Questionnaire-9 (PHQ-9), ${ }^{5}$ a measure validated for the assessment of depression in primary care populations and which allows a diagnosis of major depression. We completed analyses of these data using SAS PROC SURVEYFREQ (SAS Inc., Cary, NC, USA) in order to appropriately analyze the NHANES data in light of the complex sampling scheme by which the data were collected.

Results of our analyses of the NHANES data showed a prevalence of HIV infection in this sample of $0.57 \%$, consistent with other estimates of the prevalence of HIV infection in the US at approximately the same time ${ }^{7}$ and a prevalence of depression (as diagnosed from the PHQ-9) of
7.6\%. The prevalence of depression in those without HIV infection was $7.5 \%$, while among those with HIV infection it was $8.5 \%$. These numbers are similar to those found in the meta-analysis discussed above, ${ }^{4}$ although they do not suggest such a substantial difference in the prevalence of depression between infected and uninfected individuals. Caution should be used in interpreting these data, as even though they were collected in a highly sophisticated way to be representative of the US population and included a substantial sample $(n=3,127)$, the absolute number of HIVinfected individuals was small $(n=19)$. These data, however, suggest that the prevalence of depression among those with HIV infection may not be dramatically greater than that observed in the general population.

Problems in evaluating the prevalence of depression in this population also arise in part from the complexities of evaluating depression in medically ill persons. For example, most depression assessment instruments include items asking about the person's energy level, appetite, or sleep - factors that may be affected by the illness or its treatment as well as by the presence or absence of depression. The prevalence of depression is generally higher among those seeking medical treatment, with estimates as high as $37 \%$ in primary-care settings, ${ }^{5,8}$ perhaps due to the fact that persons who seek medical help are more likely to be distressed than those who do not seek help. Estimates of the prevalence of depression in those with HIV infection may thus be affected by which symptoms of depression are used to diagnose it and the characteristics of the individuals evaluated (such as clinic versus general population). It appears likely that significant numbers of persons with HIV infection suffer from depression. In spite of the high rates of depression in persons with HIV infection, evidence shows that it is under-recognized and under-treated. ${ }^{9,10}$

\section{Symptoms of depression in HIV infection}

Given the effects of HIV infection on physical symptoms such as fatigue, weight loss, and sleep disturbance, it may be difficult for clinicians to disentangle the extent to which such symptoms result from the illness itself or depression. In one study, the elimination of somatic items from 2 depression-rating scales improved their usefulness, ${ }^{11}$ and in other contexts, such as the evaluation of the elderly or medically ill, similar strategies have been helpful. The risk of deemphasizing the impact of depression on physical symptoms creates the possibility that some cases of depression may not be identified. 
Since it is likely that HIV infection can itself cause depression either via psychological mechanisms such as self-blame, guilt, via social mechanisms such as loss of support, or via biochemical mechanisms such as elevated neuroinflammatory markers, this distinction is likely to be artificial and arise from the mistaken idea that depression is either purely psychological or mental and that HIV infection has purely physical manifestations. Attempts to disentangle these issues may be futile and simply serve to maintain the artificial distinction between depression as a purely mental phenomenon and HIV infection-related symptoms as the result of a "real" disease. This distinction may thus obscure the essential clinical question of whether a specific patient would benefit from treatment for HIV infection.

Perhaps the most important aspect of depression in HIVpositive individuals is the occurrence of suicidal ideation and suicide. Suicidal thoughts are common in individuals with HIV infection; in one study $27 \%$ of participants over age 40 had thought about killing themselves in the previous week, ${ }^{12}$ while a similar study with a broader sample of HIV-positive individuals showed that $19 \%$ had thought about suicide during the previous week. ${ }^{13}$ In the second study, the occurrence of suicidal ideation was related to perceived social support, highlighting the importance of this factor in improving patients' mood (see below). Since suicide is a preventable cause of death, and suicide attempts can be associated with considerable morbidity even when they are nonlethal, every clinician should be skilled in eliciting suicidal ideation, intent, and plan from patients with depression and be prepared to act upon their assessment. Resources for the assessment and management of suicidality in patients are available in professional journals ${ }^{14}$ and on the Internet. ${ }^{15}$

\section{Neuroinflammation}

One important mechanism by which HIV infection may be related to depression is via inflammatory mechanisms. HIV infection is associated with increased levels of inflammatory markers, ${ }^{16,17}$ and effective antiretroviral treatment can decrease levels of inflammation. ${ }^{18}$ The neurotropic theory of depression and antidepressant treatment ${ }^{19}$ suggests that depression may be related to neuroendocrine and neuroimmunological factors and that effective treatment may address them. Large studies have linked inflammation to the development of depression. ${ }^{20}$ Given the positive effect of exercise in depression in $\mathrm{HIV}^{21}$ and evidence that exercise has positive effects on inflammation, ${ }^{22}$ one mechanism by which HIV may be etiologically linked to high rates of depression may be through the infection's effect on inflammation as may be true in cognitive aging. ${ }^{23}$ Antidepressants can address these factors and may, in fact, be neuroprotective. ${ }^{24}$

In light of the possible role of neuroinflammation in the genesis of depression, it is logical to ask whether antiretroviral treatment may reduce neuroinflammation and thus improve depression. Existing data suggest, unfortunately, that even though patients are successfully treated with combination antiretroviral therapy (CART), high levels of inflammation persist in their central nervous systems. ${ }^{25}$ The relation between depression and antiretroviral treatment may be complex and mediated in part by patient adherence to medication regimens. Depression has a negative effect on antiretroviral adherence, while treatment of depression can improve adherence, ${ }^{26}$ suggesting that the relation between immune status and depression may be mediated by behavior. Yet another behavioral and neurochemical confounder is substance abuse. Depressed patients are more likely to use substances that themselves have a negative impact on their immune status. ${ }^{27}$

\section{Depression and cognition in HIV}

The impact of depression on neurocognitive functioning in HIV negative individuals is not yet completely understood, and previous research findings have been inconsistent. ${ }^{28,29}$ While numerous studies have connected deficits in executive functioning, attention and concentration, memory, and processing speed with depression, ${ }^{29}$ it is clear that not everyone with depression has cognitive impairment. The already complex relationship between cognition and depression is even more complex when these 2 factors are considered in the context of HIV infection which itself has a direct impact on the central nervous system. The pathogenesis of HIV and depression may both involve frontostriatal circuits in the brain, ${ }^{30,31}$ but there is little agreement about the neural mechanisms that may mediate the cognitive deficits seen in depression and HIV infection. ${ }^{29}$

Earlier there was controversy about whether depression alone could account for the neuropsychological deficits seen in HIV-infected individuals. After review of research showing a dissociation between improvement in depressive symptoms from improvement in neuropsychological test performance, it is now generally accepted that HIV causes neuropsychological deficits. ${ }^{32}$

Waldrop-Valverde, Ownby and Kumar ${ }^{33}$ examined the impact of depression and HIV serostatus on neuropsychological test performance in a sample of injecting drug users (IDUs). Their sample was composed of 100 male and female IDUs that were categorized into nondepressed, 
mildly depressed, and moderate to severely depressed groups. Results of this study showed that regardless of serostatus, lower scores on cognitive measures were associated with moderate to severe depression. These findings suggest that severe depression may compromise cognition to a degree after which HIV infection does not result in additional impairment.

Sadek et $\mathrm{al}^{32}$ investigated the impact of methodological functioning and depressed mood on functional complaints in 362 HIV-positive individuals with and without methamphetamine dependence. Their results showed that the subjective experience of decline was associated with depressive symptoms, and depressive symptoms predicted cognitive complaints. The authors concluded that while it was not possible to establish whether depressive symptomatology caused an increase in cognitive deficits, self-reported functional impairment was better explained by factors such as neuropsychological test performance.

Cysique et $\mathrm{al}^{30}$ examined the incidence of major depression and its impact on the neuropsychological functioning in a longitudinal study of 98 HIV-infected men. Strengths of their study included the use of multiple measures of depression, including a structured interview and self-report measures of depression and anxiety, and a comprehensive battery of neuropsychological tests. Their findings indicated that the incidence of major depression was associated with increases in reported depressed mood and neurocognitive complaints, but that these were not associated with increased cognitive impairment.

Applebaum et $\mathrm{al}^{34}$ also examined the contributors of neuropsychological impairment in HIV-positive and HIVnegative patients who were substance dependent. Their sample included 160 opiate-dependent outpatients on methadone treatment. They were assessed using structured clinical interviews and a battery of neuropsychological tests. While HIV-infected participants displayed significantly deficient neuropsychological test performances relative to opiate-dependent controls, the results failed to support the hypothesis that neuropsychological impairment could be associated independently with comorbid depression.

Taken together, these studies show an inconsistent relationship between depression and HIV infection. Methodological differences with respect to the measurement of depression and whether or not it was a primary variable of interest further complicate attempts to synthesize extant findings. Severe depression may exacerbate neurocognitive dysfunction in individuals with other factors contributing to impairment, and substance abuse may be an important factor linking depression, immune function, and cognition. Future studies should include longitudinal designs with multiple measures of depression and comprehensive neuropsychological batteries.

\section{Depression and disease progression}

Since the advent of CART, HIV disease progression has been largely controlled by the extent to which a patient can adhere to his or her individual medication regimen. Since adherence to CART is a lifelong endeavor, focus on modifiable factors that may reduce optimal adherence is essential. Depression has been related to poor medication adherence and can thus indirectly lead to poorer disease outcomes. A number of crosssectional and some longitudinal studies have linked depressive symptoms to reduced CART adherence. ${ }^{35,36}$ Some reports suggest that incident depression across a given treatment period is more likely to affect adherence than baseline depression predicting subsequent adherence levels, ${ }^{37}$ implying that it is the acute experience of depression that limits adherence rather than a history of or a predisposition to depression.

While depression may reduce antiretroviral adherence, evidence also shows that depression may have a more direct effect on disease progression. It has been shown that negative mood states, such as major depression and depressive symptoms, may adversely impact immunological functioning of medically healthy individuals. ${ }^{38,39}$ In particular, depression severity has been associated, in vitro, with lower $\mathrm{CD}^{+}$ $\mathrm{T}$ lymphocytes and NK cell activity. ${ }^{40}$ Clinical studies of depression thus show that in the absence of other medical conditions, negative mood is associated with significant alterations in $\mathrm{CD}^{+}$and $\mathrm{NK}$ cell function.

These immune subpopulations are likely to be key in regulating HIV infection and disease progression. However, studies that have assessed the effects of depression on immune function in HIV infection have yielded inconsistent results. This may be due, in part, to differing measurements of depression, its symptoms, immune markers, and other methodological variations. For instance, although one study found no association between depression and HIV-disease stage, $\mathrm{CD}^{+}$or $\mathrm{CD}^{+}$cells of a 6 -month period, ${ }^{41}$ another study found hopelessness, one dimension common to depression, to be significantly related to decreases in $\mathrm{CD}^{+}$cell counts across 6 and 12 months. ${ }^{42}$

Results of studies relating depression with HIV disease progression and mortality over longer follow-up periods have produced mixed results. Men who have sex with men (MSM) who had elevated levels of depression at study entry had a significantly accelerated decline in $\mathrm{CD}^{+}$levels over 
5.5 years compared with those with lower levels. The effect of depression was strongest for those who had the highest CD4 ${ }^{+}$counts at baseline. ${ }^{43,44}$ Another study, however, that followed a group of MSM for 8 years found no relationship between initial depression and decline in $\mathrm{CD}^{+}{ }^{+}$cells or risk of developing AIDS. ${ }^{45}$ Still other studies have found that depression has significant effects on the immune system. As summarized by Cruess et $\mathrm{al}^{46}$ data from the Coping in Health and Illness Project (CHIP), which followed HIVinfected men for up to 9 years, show that psychosocial stress, including depressive symptoms, was associated with decrements in killer lymphocytes and declines in number of lymphocytes. Particularly in cases with both high stress and high levels of depression, faster disease progression to AIDS in men was found at 3.5 years, 5.5 years, 7.5 years, and 9 years, after adjusting for baseline viral load and $\mathrm{CD}^{+}$ cell counts.

In conclusion, nearly 2 decades of research suggest that depression may adversely impact immune function and may accelerate HIV disease progression, in addition to the indirect influence of depression on health care behaviors such as medication adherence. Future studies to better define underlying mechanisms are needed, as well as interventions to reduce depressive symptoms in an effort to slow the course of HIV disease progression.

\section{Social factors and depression}

Since the onset of the epidemic, aside from being a medical condition, HIV has been associated with a high level of stigma for infected individuals. They have often been blamed for the disease and its effects, as though they were personally culpable. This stigma can be internalized and cause patients to have feelings of shame about having a condition whose modes of transmission include sexual contact and drug use. These are 2 factors subject to social judgments about the acceptability of specific behaviors. Herek, Capatanio, and Widamen ${ }^{47}$ reported that nearly $25 \%$ of respondents believed that people who got HIV from sex or drug use "got what they deserved" (p 372). Although support for extremely punitive policies toward persons with HIV has declined, HIV infection remains a stigmatized condition worldwide.

\section{Stigma and depression}

Research on HIV-related stigma has identified links between stigma and depression. ${ }^{48,49}$ HIV-related stigma may be experienced in different ways by different populations. For example, the stress related to the stigmatization gay people experience has negative effects on their mental health, but the added emotional burden of concern over disclosing one's sexual orientation combined with HIV status can result in depression. ${ }^{50}$ Although the gay community can offer its members support, HIV-stigma exists within the gay community itself and is associated with increased levels of anxiety, loneliness, and depressive symptoms. ${ }^{48}$ Heckman et $\mathrm{al}^{51}$ examined psychological symptoms in HIV-infected adults aged 50 and older, $25 \%$ of whom reported moderate or severe levels of depression, and found these symptoms to be associated with increased barriers to care due to HIV-related stigma. HIV-related stigma is thus a psychosocial phenomenon that is experienced differently from person to person. It is unclear how it affects the mental health of different groups, and further research is needed to develop instruments designed to measure HIV stigma and its relation to depression, and to evaluate them in relevant populations.

\section{Social support}

HIV stigma can negatively influence interactions with family, friends, sexual partners, coworkers, and health professionals and often results in loss of social support. Some HIV-infected persons do not have an adequate support network because they fear rejection from family members or friends. ${ }^{52}$ Risk for suicide may be increased when HIV disclosure to loved ones is met with rejection rather than support. ${ }^{12}$ One study found that being in a current intimate relationship was associated with lower risk for depression in persons with HIV infection. ${ }^{53}$ It is likely that strong and stable social support networks are important in ameliorating the effects of HIV-related stigma. ${ }^{54}$

Stigma is an interactional process that exists within a specific social or cultural context. One study of Asian and Pacific Islanders living with HIV found high levels of internalized stigma in participants. They thus avoided seeking support because they were afraid of disclosing their status and felt unworthy of receiving support. ${ }^{55}$ In contrast to this finding, for some gay men, HIV status disclosure is related to greater quality of social support, greater self-esteem, and lower levels of depression. ${ }^{54} \mathrm{HIV}$-positive gay men who feel heavily stigmatized are thus less likely to reveal their sexual orientation or serostatus to others. They are then more likely to experience increased psychological stress after having closed off access to the precise social support needed to facilitate their adaptation to the illness. For some women, relationships within the family can often be unsupportive, and family members may take out their anger on the HIV-infected woman due to frustration resulting from 
stigmatization, the woman's lifestyle, or burden of having to care for her children. ${ }^{52}$ Other researchers have cited that women living with HIV often encounter stigmas associated with the perception of being sexually promiscuous or as vectors for HIV transmission. ${ }^{56}$ An understanding of the role of stigma in depression must thus include a consideration of the social and cultural context in which it occurs.

More research is needed to more clearly assess the nature of relationships among HIV stigma and depression and relevant mediators such as social support in HIV-positive individuals. Treatments that address the association between stigma and depression and help patients obtain social support could be useful in intervening in depression among persons with HIV infection.

\section{Assessment of depression}

A large number of rating scales are available for the assessment of depression in patients. The Beck Depression Rating Scale $^{57}$ is widely used in clinical settings and includes an assessment of both somatic (eg, fatigue) as well as cognitive (eg, guilt) aspects of depression, and a shorter form has been developed for use in primary care. ${ }^{58}$ This scale includes an item specifically asking patients about the occurrence of suicidal ideation. Another instrument that is likely to be useful in the assessment of depression in HIV-positive patients is the PHQ-9. The use of 2 of the items from this questionnaire is useful as a screening strategy for depression in primary care, ${ }^{59}$ and scores on the measure are sensitive to changes in patients' functioning. ${ }^{60}$ The PHQ-9 has been used in a project that has developed a treatment algorithm for depression that demonstrated effectiveness. ${ }^{61}$ Interested clinicians may find the materials on the website of the MacArthur Initiative on Primary Care ${ }^{62}$ helpful in assessing and treating depression in their patients. Printable versions of the PHQ-9 and treatment manuals are available on the site for download. An excellent review of these scales as well as other most suitable to children, adolescents, and the elderly is provided by Sharp and Lipsky. ${ }^{63}$

\section{Treatment}

Treatments for depression in HIV infection include pharmacologic treatment with antidepressant and other medications, psychotherapy, and a variety of complementary or alternative approaches. It should be noted that as with the treatment of depression in other populations, a number of treatments for depression are not approved by the US Food and Drug Administration for the treatment of depression. All treatments for depression are associated with risks as well as benefits; several treatments that have been investigated for depression in HIV-positive individuals may be associated with increased risks for at least some individuals.

\section{Antidepressant medications}

For many medical practitioners, antidepressant medications will be the mainstay of treatment for depression. Consistent with the broad review of issues related to depression in persons with HIV infection, this review of medications will focus mainly on general treatment issues. The reader interested in a more detailed review of medications is referred to several excellent and thorough reviews ${ }^{64-67}$ of the use of antidepressant medications in persons with HIV infection and depression. A large number of currently available antidepressant medications have been evaluated in HIV-positive individuals with indications that they are equally effective in HIV-positive individuals as in other patient groups. This section will present an overview of data on the use of the major classes of antidepressant medications in HIV infection and important contraindications for several antidepressants in the context of antiretroviral treatment.

\section{SSRIS}

Serotonin reuptake inhibitors have been shown to be effective in HIV-positive individuals. ${ }^{64,68,69}$ Among the most useful may be citalopram and sertraline due to their availability as generics and because of relatively few drug interactions with medications commonly used to treat HIV infection. There is little information on the relative usefulness of any of these drugs in treating depression in HIV-positive individuals, and the choice of antidepressant medication may generally be guided by a medication's likely side effects and potential interactions with other medications.

\section{Bupropion}

Bupropion may be useful in treatment of HIV-related depression due to its putative effect on the dopaminergic system and the likely positive effects of this action on mood, apathy, and fatigue. Biological studies have shown that dopaminergic activity is reduced in critical brain areas in HIV infection, ${ }^{70}$ and thus use of a dopaminergic medication such as bupropion has considerable appeal. Currier, Molina, and Kato ${ }^{71}$ reported on a trial of bupropion in HIV-positive individuals and suggested that it may be an effective treatment for depression in this population. Other evidence shows, however, that several widely used antiretroviral medications may affect bupropion metabolism ${ }^{72-74}$ and thus clinically relevant drug interactions may exist. Clinicians should be aware of these 
possible drug interactions and monitor patients closely for adverse effects and other signs of drug toxicity.

\section{Other antidepressants}

A variety of other antidepressants have been used in HIVrelated depression. Some may have substantial interactions with antiretrovirals (eg, nefazodone, fluvoxamine), and the treating clinician should be alert to this possibility.

\section{Testosterone and DHEA}

Several studies have suggested that testosterone or DHEA supplementation may have a positive effect on mood in men infected with HIV. ${ }^{75-77}$ Testosterone supplementation may be useful in preventing muscle wasting in HIV-positive individuals, and it may thus be a useful adjunct to other treatments for depression. As with many other treatments for depression, the use of testosterone is associated with significant risks that should be adequately considered and monitored by treating clinicians.

\section{Stimulants}

Similarly, several studies have suggested that stimulant treatment may be useful in HIV infection. Both dextroamphetamine $^{78}$ and methylphenidate have been useful. ${ }^{79,80}$ The use of stimulant medications may be associated with the risk of relapse in persons with a history of substance abuse, and thus clinicians should take this factor into account in prescribing these medications.

\section{Complementary and alternative interventions}

A variety of complementary and alternative medicine (CAM) treatments have been used for depression in HIV-infected individuals, and data suggest that HIV-infected individuals commonly use a variety of CAM interventions.$^{81}$ One study suggested that exercise might improve the effects of testosterone therapy on mood. ${ }^{21}$ Other treatments, including massage, chiropractic, and acupuncture have been reported to be useful in persons with HIV-associated depression, but clinical trials to support these reports are lacking. ${ }^{65}$

\section{CBT and other psychotherapy interventions}

While the utility antidepressant medication therapies for HIV patients has been widely studied, few published studies have investigated the efficacy of cognitive behavioral therapy (CBT) or similar specific psychotherapies for the treatment of depression in patients with HIV disease. At present, much of what little extant research there is on the subject is relatively dated, with many of the studies having been conducted more than 12 years ago. Further, most studies used disparate and inadequately detailed psychotherapeutic techniques with too few outcome measures. Many of the studies that will be discussed in the following review included depression as a secondary outcome measure. It is important to note that since stress management studies predominate the small number of studies in this area, and these approaches, theoretically based on CBT, were also included in this review. ${ }^{82}$

Himelhoch, Medoff and Oyeniy ${ }^{83}$ conducted a review and meta-analysis of the efficacy of group psychotherapy and reducing depressive symptoms in HIV-positive individuals. Included in the meta-analysis were eight clinical trials, of which 5 utilized cognitive behavioral therapy, 2 used supportive psychotherapy interventions, and 1 used a coping effectiveness training intervention. These authors report a significant and moderate effect size for CBT $(0.37,95 \%$ CI: 0.18-0.56) and a nonsignificant effect size for supportive psychotherapy (0.58, 95\% CI: 0.05-1.22).

Another review by Ferrando and Freyberg ${ }^{84}$ identified only 5 psychotherapy studies of HIV-positive individuals that included depression as a primary or secondary endpoint. Of these studies, 4 used data that was more than 12 years old, and although all of them used structured depression scales, most used different scales. Findings from these studies were inconsistent. The studies compared various contrasts of interpersonal, cognitive-behavioral, and supportive psychotherapy as well as combined treatment with medication. In spite of methodological differences among studies, this review suggested that interpersonal or cognitive behavioral therapy might be effective treatments for depression in HIV-positive individuals.

In another paper, Brown and Vanable ${ }^{82}$ reviewed 21 studies of cognitive behavioral stress management (CBSM) interventions for persons with HIV infection. Of the 21 studies, 11 of them directly measured changes in depressive symptoms. Of these 11, 5 found a significant effect of a stress management intervention on depressive symptoms, with 2 more identifying a borderline significant effect on depression in the treatment groups. Taken together, these results suggest that CBSM may be useful in the treatment of depression in HIV-positive individuals.

One recent study was not included in these reviews and thus will be discussed in greater detail here. A study by Safren et $a l^{85}$ was a randomized controlled trial to assess the effectiveness of CBT to improve both depression and medication adherence. It was one of the few trials that did not 
exclude patients with serious mental illness. Results indicated treatment-related improvements in depressive symptoms and adherence persisted 6 and 12 months after the study intervention. Findings continued to provide support for CBT for the treatment of HIV-positive people concurrently grappling with both depression and adherence. As Safren et al ${ }^{85}$ point out, a weakness of their study was the lack of an attention-matched control group. The same weakness has been found in many of the studies included in this review, as most control groups, even those receiving attention in the form of an educational seminar, did not have equivalent levels of attention compared with the experimental treatment groups. Importantly, despite the substantial improvement many patients still had significant levels of depression after treatment. This suggests that more effective therapeutic techniques are still needed.

\section{Social or group interventions}

Social support interventions are grounded in the idea that increasing support allows people to better cope and thus have fewer psychological problems. Support provided in the form of self-help groups may be most effective for persons affected by such stigmatized diseases such as HIV and mental illness since they result in the loss of support networks and increase the need for support. As noted above in a previous section, cognitive-behavioral stress management has been shown to have a positive effect on depression and immune status in HIV-positive men. ${ }^{82,86,87}$

Internet support groups (ISGs) enable persons with specific health problems to readily communicate online. The Internet, by providing access to online support groups and chat rooms, may provide a potentially very useful form of social support for persons who live in rural and other isolated populations, as well as for those who desire anonymity, such as persons with HIV. Kalichman et $\mathrm{al}^{88}$ for example, completed a randomized clinical trial of an intervention to improve information use among people living with HIV. Adults were placed in either an 8-session intervention that focused on Internet information consumer skills or a timematched support group and were followed to 9 months postintervention. The Internet skills group demonstrated greater Internet use for health, information coping, and social support compared with the control group, showing that this type of intervention might be useful in providing social support and reduce depression.

Another Internet-based intervention, the Tailored Interventions for Management of Depressive Symptoms (TIDES), provided tailored and computer-based education on key information elements and self-care strategies for persons with depressive symptoms who are living with HIV infection. ${ }^{89}$ The intervention included several interventions, such as a focus on self-empowerment through participating in the interactive process to generate their depression care plan. Preliminary results show that TIDES was accepted and used by persons living with HIV. Although results of these studies are promising, further development and testing of Internet interventions for depression in persons with HIV is needed.

Peer support has been thought to alleviate depressive symptoms through the provision of social support. One study ${ }^{90}$ evaluated the efficacy of a peer-led social support intervention involving support groups to enhance antiretroviral medication adherence, social support, and depressive symptomatology. Results showed no differences in any outcome measure between intervention conditions at immediate post-intervention or follow-up. However, post hoc analyses within the intervention condition showed that greater exposure to the intervention was associated with higher self-reported adherence, higher social support, and lower depressive symptomatology at follow-up. More high-quality randomized controlled trials of the efficacy of all types of support groups to decrease depression in HIVinfected persons are needed.

\section{Community interventions}

We found no readily identifiable empirically based community interventions addressing HIV-infected persons and depression. Most studies have targeted high-risk groups for the purpose of developing individual or small group interventions, and little research is being done on the social determinants of depression in HIV-infected individuals even though stigma and lack of support are important factors in it. It is increasingly recognized that treating HIV and comorbid psychiatric illnesses involves complex and multidimensional processes. Interventions and treatments for depression in HIV-positive persons might be more successful if they address how HIV is experienced, understood, and managed by individuals who experience both HIV-stigma and depression. Health care and service providers on all levels should be educated on HIV stigma and its impact on the psychological wellbeing of all persons living with HIV. Also, they should conduct thorough screening assessments with their HIV patients. Successful media and social marketing campaigns can raise awareness of HIV in communities and reinforce the need for educational programs while promoting respect and validation for HIV persons as a group. 


\section{Conclusion}

Depression in persons with HIV infection is a multidimensional disorder affected by a variety of biological, psychological, and social determinants. Depression is a critically important problem not only because of the misery it causes but also because it has a negative impact on treatment adherence and the immune system. Depression may affect cognitive function in persons with HIV infection, and antidepressants may have a neuroprotective effect in the illness. Data suggest that depression is under-recognized and under-treated in HIVinfected individuals. Given the availability of simple self-report screening instruments for use in primary care, neglect of this aspect of care for persons with HIV infection is reprehensible. It is particularly problematic given the availability of effective treatments. At the individual level, effective pharmacologic and psychotherapeutic interventions exist. Widely available antidepressant medications, especially the serotonin reuptake inhibitors, are useful in treating depression as is cognitivebehavioral therapy. Current research shows that group- and Internet-based interventions may be helpful in providing the social supports that many affected individuals lack and which may reduce the impact of stigma on mood in HIV-positive individuals. Current interventions are thus effective and merit wider use not only to improve patients' quality of life but also to promote better treatment outcomes.

\section{Disclosure}

The authors report no conflicts of interest in this work.

\section{References}

1. Sherbourne CD, Hays RD, Fleishman JA, et al. Impact of psychiatric conditions on health-related quality of life in persons with HIV infection. Am J Psychiatry. 2000;157:248-254.

2. Bing EG, Burnam MA, Longshore D, et al. Psychiatric disorders and drug use among human immunodeficiency virus-infected adults in the United States. Arch Gen Psychiatry. 2001;58:721-728.

3. Orlando M, Burnam MA, Beckman R, et al. Re-estimating the prevalence of psychiatric disorders in a nationally representative sample of persons receiving care for HIV: results from the HIV Cost and Services Utilization Study. Int J Methods Psychiatr Res. 2002;11:75-82.

4. Ciesla JA, Roberts JE. Meta-analysis of the relationship between HIV infection and risk for depressive disorders. Am J Psychiatry. 2001;158: 725-730.

5. Spitzer RL, Williams JB, Kroenke K, Hornyak R, McMurray J. Validity and utility of the PRIME-MD patient health questionnaire in assessment of 3000 obstetric-gynecologic patients: the PRIME-MD Patient Health Questionnaire Obstetrics-Gynecology Study. Am J Obstet Gynecol. 2000;183:759-769.

6. Centers for Disease Control and Prevention (CDC), National Center for Health Statistics (NCHS). National Health and Nutrition Examination Survey Data. Hyattsville, MD: US Department of Health and Human Services; 2005.

7. Centers for Disease Control and Prevention (CDC). HIV prevalence estimates - United States, 2006. Morb Mortal Wkly Rep. 2008;57: 1073-1076.
8. McQuaid JR, Stein MB, Laffaye C, McCahill ME. Depression in a primary care clinic: the prevalence and impact of an unrecognized disorder. J Affect Disord. 1999;55:1-10.

9. Asch SM, Kilbourne AM, Gifford AL, et al. Underdiagnosis of depression in HIV: who are we missing? J Gen Intern Med. 2003; 18:450-460.

10. Pyne JM, Asch SM, Lincourt K, et al. Quality indicators for depression care in HIV patients. AIDS Care. 2008;20:1075-1083.

11. Kalichman SC, Rompa D, Cage M. Distinguishing between overlapping somatic symptoms of depression and HIV disease in people living with HIV-AIDS. J Nerv Ment Dis. 2000;188:662-670.

12. Kalichman SC, Heckman T, Kochman A, Sikkema K, Bergholte J. Depression and thoughts of suicide among middle-aged and older persons living with HIV-AIDS. Psychiatr Serv. 2000;51:903-907.

13. Carrico AW, Johnson MO, Morin SF, et al. Correlates of suicidal ideation among HIV-positive persons. AIDS. 2007;21:1199-1203.

14. Gliatto MF, Rai AK. Evaluation and treatment of patients with suicidal ideation. Am Fam Physician. 1999;59:1500-1506.

15. Suicide Prevention Resource Center [homepage on the Internet]. Newton, MA: Education Development Center Inc.; c1994-2009. Available from: http://www.sprc.org/. Accessed 2010.

16. Ownby RL, Kumar AM, Benny FJ, et al. Tumor necrosis factor-alpha levels in HIV-1 seropositive injecting drug users. J Neuroimmune Pharmacol. 2009;4:350-358.

17. Decrion AZ, Dichamp I, Varin A, Herbein G. HIV and inflammation. Current HIV Research. 2005;3:243-259.

18. Henry K, Kitch D, Dube M, et al. C-Reactive protein levels over time and cardiovascular risk in HIV-infected individuals suppressed on an indinavir-based regimen: AIDS Clinical Trials Group 5056s. AIDS. 2004; 18:2434-2437

19. Nestler EJ, Hyman SE, Malenka RC. Molecular Neuropharmacology: A Foundation for Clinical Neuroscience. 2nd ed. New York: McGraw-Hill; 2009.

20. Gimeno D, Kivimaki M, Brunner EJ, et al. Associations of C-reactive protein and interleukin-6 with cognitive symptoms of depression: 12-year follow-up of the Whitehall II study. Psychol Med. 2009;39:413-423.

21. Wagner G, Rabkin J, Rabkin R. Exercise as a mediator of psychological and nutritional effects of testosterone therapy in HIV+ men. $\mathrm{Med} \mathrm{Sci}$ Sports Exerc. 1998;30:811-817.

22. Cotman CW, Berchtold NC, Christie LA. Exercise builds brain health: key roles of growth factor cascades and inflammation. Trends Neurosci. 2007;30:464-472.

23. Ownby RL. Neuroinflammation and cognitive aging. Curr Psychiatry Rep. 2010;12:39-45

24. Ances BM, Letendre SL, Alexander T, Ellis RJ. Role of psychiatric medications as adjunct therapy in the treatment of HIV associated neurocognitive disorders. Int Rev Psychiatry. 2008;20:89-93.

25. Anthony IC, Ramage SN, Carnie FW, Simmonds P, Bell JE. Influence of HAART on HIV-related CNS disease and neuroinflammation. J Neuropathol Exp Neurol. 2005;64:529-536.

26. Horberg MA, Silverberg MJ, Hurley LB, et al. Effects of depression and selective serotonin reuptake inhibitor use on adherence to highly active antiretroviral therapy and on clinical outcomes in HIV-infected patients. J Acquir Immune Defic Syndr. 2008;47:384-390.

27. Anthony IC, Arango JC, Stephens B, Simmonds P, Bell JE. The effects of illicit drugs on the HIV infected brain. Front Biosci. 2008;13: 1294-1307.

28. Gualtieri CT, Johnson LG, Benedict KB. Neurocognition in depression: patients on and off medication versus healthy comparison subjects J Neuropsychiatry Clin Neurosci. 2006;18:217-225.

29. McClintock SM, Husain MM, Greer TL, Cullum CM. Association between depression severity and neurocognitive function in major depressive disorder: a review and synthesis. Neuropsychology. 2010;24:9-34.

30. Cysique LA, Deutsch R, Atkinson JH, et al. Incident major depression does not affect neuropsychological functioning in HIV-infected men. J Int Neuropsychol Soc. 2007;13:1-11.

31. Tekin S, Cummings JL. Frontal-subcortical neuronal circuits and clinical neuropsychiatry: an update. J Psychosom Res. 2002;53:647-654. 
32. Sadek JR, Vigil O, Grant I, Heaton RK; for the HNRC Group. The impact of neuropsychological functioning and depressed mood on functional complaints in HIV-1 infection and methamphetamine dependence. J Clin Exp Neuropsychol. 2007;29:266-276.

33. Waldrop-Valverde D, Ownby RL, Kumar M. Influence of depression and HIV serostatus on the neuropsychological performance of injecting drug users. Psychiatry Clin Neurosci. 2005;59:372-378.

34. Applebaum AJ, Otto MW, Richardson MA, Safren SA. Contributors to neuropsychological impairment in HIV-infected and HIV-uninfected opiate-dependent patients. J Clin Exp Neuropsychol. 2009 Nov 4; $1-11$.

35. Ammassari A, Antinori A, Aloisi MS, et al. Depressive symptoms, neurocognitive impairment, and adherence to highly active antiretroviral therapy among HIV-infected persons. Psychosomatics. 2004;45: 394-402.

36. Waldrop-Valverde D, Valverde E. Homelessness and psychological distress as contributors to antiretroviral nonadherence in HIV-positive injecting drug users. AIDS Patient Care STDS. 2005;19:326-334.

37. Kacanek D, Jacobson DL, Spiegelman D, Wanke C, Isaac R, Wilson IB. Incident depression symptoms are associated with poorer HAART adherence: a longitudinal analysis from the Nutrition for Healthy Living study. J Acquir Immune Defic Syndr. 2010;53:266-272.

38. Evans D, Petitto J, Leserman J, et al. Stress, depression and natural killer cells: potential clinical relevance. Clin Neuropharmacol. 1992; 15 Suppl 1 (Pt A):656A-657A.

39. Evans DL, Leserman J, Pedersen CA, et al. Immune correlates of stress and depression. Psychopharmacol Bull. 1989;25:319-324.

40. Herbert TB, Cohen S. Depression and immunity: a meta-analytic review. Psychol Bull. 1993;113:472-486.

41. Rabkin JG, Williams JB, Remien RH, Goetz R, Kertzner R, Gorman JM. Depression, distress, lymphocyte subsets, and human immunodeficiency virus symptoms on two occasions in HIV-positive homosexual men. Arch Gen Psychiatry. 1991;48:111-119.

42. Perry S, Fishman B, Jacobsberg L, Frances A. Relationships over 1 year between lymphocyte subsets and psychosocial variables among adults with infection by human immunodeficiency virus. Arch Gen Psychiatry. 1992;49:396-401.

43. Barrett DC, Chesney MA, Burack JH, Stall RD, Ekstrand ML, Coates TJ. Depression and CD4 decline. JAMA. 1994;271:1743-1744.

44. Burack JH, Barrett DC, Stall RD, Chesney MA, Ekstrand ML, Coates TJ. Depressive symptoms and CD4 lymphocyte decline among HIVinfected men. JAMA. 1993;270:2568-2573.

45. Lyketsos CG, Hoover DR, Guccione M, et al. Depressive symptoms as predictors of medical outcomes in HIV infection. Multicenter AIDS Cohort Study. JAMA. 1993;270:2563-2567.

46. Cruess DG, Petitto JM, Leserman J, et al. Depression and HIV infection: impact on immune function and disease progression. CNS Spectr. 2003;8:52-58.

47. Herek GM, Capitanio JP, Widaman KF. HIV-related stigma and knowledge in the United States: prevalence and trends, 1991-1999. Am J Public Health. 2002;92:371-377.

48. Courtenay-Quirk C, Wolitski RJ, Parsons JT, Gomez CA. Is HIV/AIDS stigma dividing the gay community? Perceptions of HIV-positive men who have sex with men. AIDS Educ Prev. 2006;18:56-67.

49. Logie C, Gadalla TM. Meta-analysis of health and demographic correlates of stigma towards people living with HIV. AIDS Care. 2009; 21:742-753.

50. Frost DM, Parsons JT, Nanin JE. Stigma, concealment and symptoms of depression as explanations for sexually transmitted infections among gay men. J Health Psychol. 2007;12:636-640.

51. Heckman TG, Heckman BD, Kochman A, Sikkema KJ, Suhr J, Goodkin K. Psychological symptoms among persons 50 years of age and older living with HIV disease. Aging Ment Health. 2002;6:121-128.

52. Robbins M, Szapocznik J, Tejeda M, Samuels D, Ironson G, Antoni M. The protective role of the family and social support network in a sample of HIV-positive African American women: results of a pilot study. J Black Psychol. 2003;29:17-37.
53. Komiti A, Judd F, Grech P, et al. Depression in people living with HIV/AIDS attending primary care and outpatient clinics. Aust $N Z J$ Psychiatry. 2003;37:70-77.

54. Chenard C. The impact of stigma on the self-care behaviors of HIVpositive gay men striving for normalcy. J Assoc Nurses AIDS Care. 2007; 18:23-32.

55. Kang E, Rapkin BD, Remien RH, Mellins CA, OhA. Multiple dimensions of HIV stigma and psychological distress among Asians and Pacific Islanders living with HIV illness. AIDS Behav. 2005;9: 145-154.

56. Lichtenstein B. Stigma as a barrier to treatment of sexually transmitted infection in the American deep south: issues of race, gender and poverty. Soc Sci Med. 2003;57:2435-2445.

57. Beck AT, Ward CH, Mendelson M, Mock J, Erbaugh J. An inventory for measuring depression. Arch Gen Psychiatry. 1961;4:561-571.

58. Beck AT, Guth D, Steer RA, Ball R. Screening for major depression disorders in medical inpatients with the Beck Depression Inventory for Primary Care. Behav Res Ther. 1997;35:785-791.

59. Kroenke K, Spitzer RL, Williams JB. The Patient Health Questionnaire-2: validity of a two-item depression screener. Med Care. 2003;41: 1284-1292.

60. Lowe B, Unutzer J, Callahan CM, Perkins AJ, Kroenke K. Monitoring depression treatment outcomes with the patient health questionnaire-9. Med Care. 2004;42:1194-1201.

61. Dietrich AJ, Oxman TE, Williams JW Jr, et al. Re-engineering systems for the treatment of depression in primary care: cluster randomised controlled trial. BMJ. 2004;329:602.

62. The MacArthur Initiative on Depression and Primary Care [homepage on the Internet]. MacArthur Foundation; c2003-2009. Available from: http://www.depression-primarycare.org/. Accessed 2010.

63. Sharp LK, Lipsky MS. Screening for depression across the lifespan: a review of measures for use in primary care settings. Am Fam Physician. 2002;66:1001-1008.

64. Caballero J, Nahata MC. Use of selective serotonin-reuptake inhibitors in the treatment of depression in adults with HIV. Ann Pharmacother. 2005;39:141-145.

65. Fulk LJ, Kane BE, Phillips KD, Bopp CM, Hand GA. Depression in HIV-infected patients: Allopathic, complementary, and alternative treatments. J Psychosom Res. 2004;57:339-351.

66. Basu S, Chwastiak LA, Bruce RD. Clinical management of depression and anxiety in HIV-infected adults. AIDS. 2005;19:2057-2067.

67. Cruess DG, Evans DL, Repetto MJ, Gettes D, Douglas SD, Petitto JM. Prevalence, diagnosis, and pharmacological treatment of mood disorders in HIV disease. Biol Psychiatry. 2003;54:307-316.

68. Rabkin JG, Wagner GJ, Rabkin R. Fluoxetine treatment for depression in patients with HIV and AIDS: a randomized, placebo-controlled trial. Am J Psychiatry. 1999;156:101-107.

69. Zisook S, Peterkin J, Goggin KJ, Sledge P, Atkinson JH, Grant I. Treatment of major depression in HIV-seropositive men. HIV Neurobehavioral Research Center Group. J Clin Psychiatry. 1998;59:217-224.

70. Kumar AM, Fernandez J, Singer EJ, et al. Human immunodeficiency virus type 1 in the central nervous system leads to decreased dopamine in different regions of postmortem human brains. J Neurovirol. 2009;1-18.

71. Currier MB, Molina G, Kato M. A prospective prial of sustained-release bupropion for depression in HIV-seropositive and AIDS patients. Psychosomatics. 2003;44:120-125.

72. Foisy M, Tseng A. Drug Interaction Tables. 2010. Toronto General Hospital. c 2010. Available from: http://www.hivclinic.ca/main/ drugs_interact.html. Accessed 2010.

73. Tseng AL, Foisy MM. Significant interactions with new antiretrovirals and psychotropic drugs. Ann Pharmacother. 1999;33:461-473.

74. Hesse LM, von Moltke LL, Shader RI, Greenblatt DJ. Ritonavir, efavirenz, and nelfinavir inhibit CYP2B6 activity in vitro: potential drug interactions with bupropion. Drug Metab Dispos. 2001;29: $100-102$.

75. Rabkin JG, Rabkin R, Wagner G. Testosterone replacement therapy in HIV illness. Gen Hosp Psychiatry. 1995;17:37-42. 
76. Rabkin JG, Wagner GJ, Rabkin R. A double-blind, placebo-controlled trial of testosterone therapy for HIV-positive men with hypogonadal symptoms. Arch Gen Psychiatry. 2000;57:141-147.

77. Rabkin JG, Ferrando SJ, Wagner GJ, Rabkin R. DHEA treatment for HIV+ patients: effects on mood, androgenic and anabolic parameters. Psychoneuroendocrinology. 2000;25:53-68.

78. Wagner GJ, Rabkin R. Effects of dextroamphetamine on depression and fatigue in men with HIV: a double-blind, placebo-controlled trial. J Clin Psychiatry. 2000;61:436-440.

79. Fernandez F, Levy JK, Samley HR, et al. Effects of methylphenidate in HIV-related depression: a comparative trial with desipramine. Int J Psychiatry Med. 1995;25:53-67.

80. Breitbart W, Rosenfeld B, Kaim M, Funesti-Esch J. A randomized, double-blind, placebo-controlled trial of psychostimulants for the treatment of fatigue in ambulatory patients with human immunodeficiency virus disease. Arch Intern Med. 2001;161:411-420.

81. Fairfield KM, Eisenberg DM, Davis RB, Libman H, Phillips RS Patterns of use, expenditures, and perceived efficacy of complementary and alternative therapies in HIV-infected patients. Arch Intern Med 1998;158:2257-2264.

82. Brown JL, Vanable PA. Cognitive-behavioral stress management interventions for persons living with HIV: a review and critique of the literature. Ann Behav Med. 2008;35:26-40.

83. Himelhoch S, Medoff DR, Oyeniyi G. Efficacy of group psychotherapy to reduce depressive symptoms among HIV-infected individuals: a systematic review and meta-analysis. AIDS Patient Care STDS. 2007;21:732-739.
84. Ferrando SJ, Freyberg Z. Treatment of depression in HIV positive individuals: a critical review. Int Rev Psychiatry. 2008;20:61-71.

85. Safren SA, O'Cleirigh C, Tan JY, et al. A randomized controlled trial of cognitive behavioral therapy for adherence and depression (CBT-AD) in HIV-infected individuals. Health Psychol. 2009;28:1-10.

86. Antoni MH, Carrico AW, Duran RE, et al. Randomized clinical trial of cognitive behavioral stress management on human immunodeficiency virus viral load in gay men treated with highly active antiretroviral therapy. Psychosom Med. 2006;68:143-151.

87. Carrico AW, Antoni MH, Duran RE, et al. Reductions in depressed mood and denial coping during cognitive behavioral stress management with HIV-Positive gay men treated with HAART. Ann Behav Med. 2006;31:155-164.

88. Kalichman SC, Cherry C, Cain D, et al. Internet-based health information consumer skills intervention for people living with HIV/AIDS. J Consult Clin Psychol. 2006;74:545-554.

89. Lai TY, Larson EL, Rockoff ML, Bakken S. User acceptance of HIV TIDES - Tailored Interventions for Management of Depressive Symptoms in persons living with HIV/AIDS. J Am Med Inform Assoc. 2008; 15:217-226.

90. Simoni JM, Pantalone DW, Plummer MD, Huang B. A randomized controlled trial of a peer support intervention targeting antiretroviral medication adherence and depressive symptomatology in HIV-positive men and women. Health Psychol. 2007;26:488-495.
Neurobehavioral HIV Medicine

\section{Publish your work in this journal}

Neurobehavioral HIV Medicine is an international, peer-reviewed, open access journal focusing on advances in research in HIV/ AIDS, with specific reference to the neurological, psychiatric and behavioral consequences of the disease, concomitant infections and specific antiretroviral therapy. The manuscript

\section{Dovepress}

management system is completely online and includes a very quick and fair peer-review system, which is all easy to use. Visit http://www.dovepress.com/testimonials.php to read real quotes from published authors.

Submit your manuscript here: http://www.dovepress.com/journal-of-neurobehavioral-hiv-medicine-journal 